\title{
The role of the natural environment in disaster recovery: "We live here because we love the bush"
}

Karen Block, Robyn Molyneaux, Lisa Gibbs, Nathan Alkemade, Elyse Baker,

Colin MacDougall, Greg Ireton, David Forbes

\begin{abstract}
This mixed-methods study explored the role of connection to the natural environment in recovery from the 'Black Saturday' bushfires that blazed across Victoria, Australia, in February 2009. Qualitative findings demonstrated that many participants had a strong connection to the natural environment, experienced considerable grief as a result of its devastation in the fires and drew solace from seeing it regenerate over the following months and years. Quantitative analyses indicated that a strong attachment to the environment was associated with reduced psychological distress, fewer symptoms of major depression and fire-related PTSD, and higher levels of resilience, post-traumatic growth and life satisfaction. While social connections are increasingly recognized as supportive of disaster recovery, the influence of landscapes also needs to be recognized in terms of the impact of their destruction as well as their therapeutic potential.
\end{abstract}

\section{Keywords}

Disaster; mental health; natural environment; recovery; biophilia; topophilia

\section{Introduction}

In early 2009, Australia experienced a major disaster, as bushfires burned across much of the state of Victoria, with the greatest destruction occurring on Saturday $7^{\text {th }}$ February. In what quickly became known as the Black Saturday Bushfires, 173 lives were lost, 430,000 hectares were burned, and 3,500 buildings (2,133 houses) were damaged or destroyed causing immense damage to the social and physical environments of thousands of people in dozens of communities (Teague et al., 2010).

The ‘Beyond Bushfires: Community, Resilience and Recovery’ study brought together investigators and partners from academia across disciplines, emergency management, health, government and community organisations to focus on the medium to long term outcomes for individuals and communities affected by the fires (www.beyondbushfires.org.au). The Beyond Bushfires study aimed to describe recovery trajectories in terms of mental health, wellbeing and social connectedness and to understand the role of social networks in 
supporting individual and community resilience and recovery. Its overall goals were to understand individual and community-level predictors of recovery to inform evidence-based support strategies and interventions both in the fires' aftermath and in future disasters.

Beyond Bushfires employed a mixed methods longitudinal study design (Gibbs et al., 2013). Community visits were conducted in the early stages of the study to gain an understanding of the community contexts and build relationships with community groups - both to aid recruitment and to inform the methodology (including the study name, ethical considerations, data collection methods and survey items). These visits continued throughout the study to gain feedback on early results and to disseminate findings. We conducted the first wave of quantitative surveys from December 2011 through January 2013 (3-4 years postdisaster). This was followed by in-depth qualitative interviews with a subsample of survey participants and a second wave of quantitative surveys from July to November 2014. The survey questions focused on bushfire exposure, mental health, wellbeing, social networks, community attachment, and individuals' relationships to community organisations.

As is evident from the description above, the investigators' primary interest in the broader Beyond Bushfires study was exploring the influence that social networks and social environments had on the recovery trajectories of individuals and communities and we designed our survey instruments to capture these phenomena. As hypothesized, we found that people's networks, level of social connectedness, and group involvement did have an impact on their mental health (Bryant et al., 2017; Gallagher et al., 2019). The qualitative component of the study however, consistent with commonly accepted inductive qualitative research paradigms, was explicitly designed (using open-ended research probes) to be driven more by the interests of the participants than those of the researchers. Using participant-guided mobile methods, we asked people to show us the places in their communities that were important to them and to talk about why those places were significant (Block et al., 2014). We were initially somewhat surprised that many of the interview participants did not take us to places that were important because of their social meaning. Instead, they often took us on a tour of their natural environment, sometimes entirely within their own properties, speaking at length about the ways in which the Australian bush - and often individual trees - had been damaged in the fires and were now regenerating. The importance of the natural environment to people's sense of place and 
wellbeing became obvious through the course of these interviews. This in turn provided the impetus for us to pursue this line of inquiry through our survey data as well. This paper focuses on these findings.

\section{Conceptualizing disaster recovery and wellbeing}

While disaster terminology varies across the literature, recovery can broadly be conceptualized as the gradual return to 'normalcy' over the longer term following a disaster event (Blackman et al., 2017; UNISDR, 2015). Smith and Wenger (2007, p. 237) define disaster recovery as 'the differential process of restoring, rebuilding, and reshaping the physical, social, economic, and natural environment through pre-event planning and post-event actions'. It is a complex non-linear phenomenon, the rate and extent of which varies across individuals, groups, organizations, communities, and environments (Blackman et al., 2017; Smith and Wenger, 2007).

Disaster scholars have invested considerable effort into developing theoretical models and frameworks for understanding and supporting disaster recovery. Such models frequently delineate a number of community capitals or resources as underpinning recovery. Although the number and composition of capitals in these frameworks vary, they commonly emphasize the primacy of social resources or of social and economic resources (Aldrich, 2012; Miles, 2015; Norris et al., 2008). Widely cited work by Norris and colleagues, for example, argues that community resilience in the context of a disaster arises from four sets of capacities: economic development, social capital, information and communication, and community competence (Norris et al., 2008). Abramson and colleagues, meanwhile, describe human, economic, social and political capital as comprising 'resilience attributes' at community and individual levels (Abramson et al., 2014). Another framework suggests that there are four wealth capitals of disaster recovery: manufactured, natural, human, and social, (Ekins et al., 2008; Lawther, 2016), with Lawther (2016) arguing that social capital should be regarded as the primary wealth capital, underpinning and permeating the others.

There are some notable (and predominantly theory-based) exceptions to this social emphasis in disaster recovery research which focus on place-attachment. This includes the theory advanced by Tidball (2012), which builds on the notion of 'biophilia' or human affinity with the natural world (Wilson, 1984), to argue that actively seeking engagement with nature represents a critical source of social-ecological resilience in the face of hardship or crisis. The edited collection, Greening in the Red Zone: Disaster, resilience and 
community greening, (Tidball and Krasny, 2014) similarly focuses on the impact of active and communal engagement in restoring nature or 'greening' activities. Cox and Perry (2011) examine the salience of place in the disaster recovery process but considered disaster-related disruption to landscape as predominantly social in meaning. While noting that their study participants expended a good deal of energy on re-greening a fireravaged environment, the damaged natural environment in this context was seen as a metaphor for other losses and changes that were fundamentally social. They argue for the importance of focusing on place 'as the ground upon which social capital and [therefore] community disaster resilience are built' (Cox and Perry, 2011). Stedman and Ingalls (2014) explore the relationship between biophilia and 'topophilia' (love of place) in Greening the Red Zone (Tidball and Krasny, 2014). They too however, argue that place attachment is fundamentally social and cultural suggesting that 'biophysical components of place are important, in many cases necessary, [but they] are not sufficient alone to engender meaningful place-attachment' (Stedman and Ingalls, 2014, p.134). Applying a seven-element community capitals framework (natural, cultural, human, social, political, financial, and built) to analysis of disaster preparedness, response and recovery, Himes Cornell and colleagues treat natural capital as a resource that is primarily important for its economic value in supporting livelihoods (Himes-Cornell et al., 2018). Mayunga and colleagues (2007) include natural capital in a five-element model, arguing that it sustains all forms of life and provides protection from weather-related hazards such as storms and floods.

Thus, the majority of scholarly efforts are generally firmly focused on the social and economic basis for disaster resilience, with the natural environment (when present in theoretical models) seen as primarily important for its role in facilitating social or economic capital or in providing protection. There appears to be relatively little research directly exploring the role of the natural environment in mediating disaster experiences and recovery. While the importance of social and economic factors is undisputed, this paucity of attention is perhaps somewhat surprising given that destruction of natural environment is an almost inevitable sequel of natural disasters. Furthermore, this loss is likely to be experienced by the whole community irrespective of individual differences in terms of loss of property or loved ones.

\section{The natural environment and health}


That people enjoy natural environments and green space is hardly a startling proposition and there is a growing literature aimed at understanding how contact with nature is linked to improved human health outcomes (Ulrich, 1984, Maller et al., 2006, Korpela et al., 2008, Kaplan, 1995, Kaplan and Kaplan, 1989, Ulrich, 1999, Stigsdotter et al., 2010, Van den Berg et al., 2010, Beyer et al., 2014). One of the most extensively studied nature therapies, is the Japanese practice of Shinrin-Yoku or 'Forest Bathing', which has been associated with a wide range of physiological and psychological health benefits (Hansen et al., 2017)

A recent systematic review of studies examining stress responses and exposure to outdoor environments concluded that spending time in those environments, particular outdoor environments with green space, may reduce the experience of stress and ultimately improve health (Kondo et al., 2018). A study which compared the restorative benefits of walking in urban and rural settings, for adults with good and poor mental health, indicated greater benefits were associated with the rural landscape. Moreover, the greatest benefits were found for those in the poor mental health group (Roe and Aspinall, 2011).

Research exploring the role of natural settings in rehabilitation from a personal crisis is particularly relevant for our study (Ottosson and Grahn, 2008). A Swedish study surveyed 547 individuals, asking them whether they had experienced a difficult event (such as divorce, a death or other severe loss) and if so, the extent to which they felt affected, along with questions about experiencing nature, taking a walk, and being with friends. Findings indicated that while social factors had more influence on rehabilitation potential for those affected by a crisis to a low or moderate degree, experiencing nature had the most powerful rehabilitative potential for people who were greatly affected by a crisis. Individuals who had many experiences of nature were less affected by their crisis than those who had few such experiences (Ottosson and Grahn, 2008).

\section{Exploring the links between the natural environment and wellbeing post-disaster}

Despite this evidence for the links between experiences of the natural environment and wellbeing, we too (as described in the introduction) were influenced by the general social emphasis within disaster resilience research and, at the outset of the Beyond Bushfires study, were primarily concerned with understanding place as a social space that would influence individual and community trajectories post-disaster. The focus of this paper represents a rare empirical exploration of connection to the natural environment as a critical factor 
influencing disaster recovery in its own right. As with disaster recovery, there is no single agreed definition or method for assessing wellbeing. For the purpose of this paper, we have conceptualized it in this context as a composite construct hat encompasses both lack of psychopathology (post-traumatic stress symptoms, depression, and psychological distress) and positive dimensions (life satisfaction, resilience, and posttraumatic growth).

\section{Methods}

The Beyond Bushfires study recruited adults residing in 25 communities in 10 locations across the state of Victoria, Australia. These communities were selected to capture diversity of bushfire impact, ranging from low impact (defined as no fatalities and limited or no damage to property), medium-impact (significant property damage with few or no fatalities), to high-impact (extensive property loss and fatalities). The Beyond Bushfires study was approved by the University of Melbourne Human Research Ethics Committee.

\section{Quantitative surveys}

For Wave 1 recruitment, census data from 2006 indicated a total adult population of 7,693 in the selected communities. A saturation sampling method was used to try to reach as many adults as possible in those communities and the Victorian Electoral Commission (VEC) supplied contact details of both current residents and those who had relocated since the 2009 bushfires $(\mathrm{N}=7467$ adults). An invitation letter was sent to each of these. Additional recruitment efforts included mailbox drops, direct phone calls, and use of news and social media to raise community awareness of the project. A total of 1,056 people (16\%) ultimately completed the survey either online or administered via Computer Assisted Telephone Interview (CATI). This sample comprised 416 males and 640 females, ranging in age from 18-87 with a mean age of $56.19(\mathrm{SD}=$ 13.33) at the time of the Wave 1 survey. Survey items covered sociodemographics, disaster exposure, life circumstances since the disaster, mental and physical health and wellbeing, community factors, and social connections.

Of the 1,056 participants who took part in the first wave of data collection, 966 agreed to be recontacted for the second wave which took place between $15^{\text {th }}$ July and 7 th November 2014. Of those who agreed to be recontacted, 736 (76\%) were retained at follow-up - 282 males and 450 females, ranging in age from 21-89 with a mean age of 58.37 ( $\mathrm{SD}=12.84)$. Only those residing in moderately or highly impacted 
communities at the time of the 2009 bushfire and who participated at both timepoints were included in the analyses for this paper (597 people).

\section{Survey measures}

Fire exposure and experiential variables. Three variables were used to measure severity of bushfire exposure: whether an individual feared for their life (yes/no), whether an individual lost someone close as a result of the fires (yes/no), and the extent to which an individual lost personal or business property/possessions, measured on a scale from 0 (nothing lost) to 10 (everything lost). A fourth experiential variable captured whether individuals had relocated since the 2009 fires.

Environmental attachment and affect. Respondents were asked to indicate the extent to which they agreed or disagreed with the following statements on a scale from 0 (strongly disagree) to 4 (strongly agree).

Wave 1 surveys:

1. In January 2009 [i.e. before the fires] I was very attached to the local environment/landscape

2. Now [i.e. 3-4 years post fires] I am very attached to the local environment and landscape.

Wave 2 surveys:

3. Now [i.e. approx. 5 years post fires] I am very attached to the local environment and landscape

4. I am unhappy with the way the natural environment has changed because of the Victorian 2009 bushfires

5. Seeing the recovery of the natural environment since the Victorian 2009 bushfires has a positive effect on me

Psychological distress. Psychological distress was assessed using the Kessler 6 (K6), an index of nonspecific psychological distress, recording symptoms of anxiety/mood disorders on a scale from 1 to $5(\alpha=.84)$ over the preceding month (Kessler et al., 2002).

PTSD. Both fire-related and general probable PTSD were assessed using the short form of the Posttraumatic Stress Disorder Checklist (Bliese et al., 2008). For each item, respondents were asked to rate how much the symptom had bothered them over the preceding four weeks, on a scale of 1 to $5(\alpha=.75)$.

Depression. Probable major depression was assessed using the Patient Health Questionnaire (Kroenke et al., 2001). An occurrence of a probable major depressive episode was recorded if five of the nine depression symptoms were reported as being present for a majority of days over the preceding two weeks $(\alpha=.83)$. 
Life Satisfaction. Individuals were asked to indicate the extent to which they were satisfied with life as a whole on a scale of 0 to 10 (Cummins et al., 2003).

Resilience. Resilience was assessed using two items drawn from the Connor-Davidson Resilience Scale (Connor and Davidson, 2003) relating to dealing with changes in life: I am able to adapt to change; and I tend to bounce back after illness or hardship. Each item was measured on a scale from 1 to $5(\alpha=.75)$.

Posttraumatic growth. Posttraumatic growth (PTG) was assessed using the ten-item short form posttraumatic growth inventory (Cann et al., 2010). Responses were recorded on a scale of 1 to 6 indicating the extent to which the participant felt they had experienced a change as a result of the Victorian 2009 bushfires $(\alpha=.88)$.

\section{Statistical analysis}

Descriptive analysis. Chi-square tests of independence, and independent group t-tests were employed to investigate demographic, exposure, and mental health variables across genders.

Latent Profile Analysis. Building on the qualitative research findings, latent profile analysis (LPA) was conducted to determine environmental attachment group membership based on participant responses to the environmental attachment questions. LPA is a form of mixture modelling that uses observed data to uncover subgroups of people. LPA assigns individuals to groups ('profiles') based on their similar responses to continuous items. LPA results are based on 'exploratory analysis', similar to an exploratory factor analysis, where no firm assumptions are made concerning the number or composition of groups. Instead LPA models are fit following a series of steps, the first of which involves specifying a single-profile model. The number of profiles is then progressively increased until there is no further improvement (or a degradation) in the fit of the model. Along with model fit, the final decision on the preferred number of profiles also considered interpretability and parsimony.

Model fit was ascertained through a series of measures. Comparative model fit was assessed using Akaike's Information Criterion (AIC) (Akaike, 1987); Bayesian Information Criterion (BIC) (Schwarz, 1978); and Adjusted BIC (ABIC) (Sclove, 1987); with smaller values denoting a better fitting model. The LoMendell-Rubin Likelihood ratio test (LMR-LRT) (Lo et al., 2001) and Bootstrap Likelihood ratio test (BLRT) (McCutcheon, 1987; McLachlan and Peel, 2000) were also employed. These tests compare the estimated 
model against a model with one less profile (the preceding model), with scores of $p<.05$ indicating the present model is a superior fit. Finally, a measurement of classification certainty, Relative Entropy, was used, with higher scores (ranging from 0-1) indicating a better fit (Celeux and Soromenho, 1996; Muthén and Muthén, 1998-2015).

The LPA model was produced using Mplus 7.3 (Muthén and Muthén, 1998-2015). Latent profiles were identified using four indicators of environmental attachment and affect, measured through the extent to which respondents agreed with four statements: 1/ I am very attached to the local environment and landscape (Wave 1), 2/ I am very attached to the local environment and landscape (Wave 2), 3/ I am unhappy with the way the natural environment has changed because of the Victorian 2009 bushfires (Wave 2), and 4/ Seeing the recovery of the natural environment since the Victorian 2009 bushfires has a positive effect on me (Wave 2). A fifth item was used as a conditional predictor of class membership: I was very attached to the local environment/landscape in January 2009 (i.e. before the fires). As this variable also related to environmental attachment (similar to the four latent profile indicator variables) it was intentionally included in the analysis while forming the latent profiles and contributed to the determination of profile membership (Clark and Muthén, 2009).

To examine the relation between profile membership and additional covariates (such as demographics, bushfire exposure, mental health, resilience and growth, and satisfaction with life), the assigned profile memberships of the individuals in the study were exported to SPSS (IBM SPSS Statistics 23). Profile differences were then examined using mean comparison tests, which for LCA/LPA with entropy over 0.8 have been reported to perform acceptably in relation to type I and type II errors (Clark and Muthén, 2009). This method of analysis was employed as these variables were not intended to contribute to the profile membership determined through the LPA, but instead the intention was to examine how these variables may compare across the environmental attachment profiles.

\section{Qualitative interviews}

Interview procedure

Following Wave 1 quantitative data collection, we recruited a subsample of survey participants along with some of their family members to participate in in-depth interviews. A purposive sampling strategy was 
used to capture a range of perspectives and demographic characteristics within high-and medium-impact communities. The interviews took place between May 2013 and August 2014 (4-5 years after the fires). Participant-guided mobile methods were used to explore interviewees' relationships (and changed relationships) with their environment and to maximise their control over the interview process (Block et al., 2014). Participants were asked to show us places that were important to them and to talk about why they had chosen those places. This method usually resulted in a walk or drive around the participant/s' property and/or local area. Some people were interviewed with family members, for example as a couple or a parent with a child, according to their preference, resulting in 25 interviews with 35 participants (including five children) with an age range of four to 66 years. The interviews were audio-recorded and subsequently transcribed with identifying information removed and replaced with a number preceded by $\mathrm{M}$ (male) or $\mathrm{F}$ (female) for reporting purposes.

\section{Interview data analysis}

NVivo 11 (QSR International, 2015) was used as a qualitative data management tool. The data analysis process involved co-coding of the transcripts by the three researchers who conducted the interviews (LG, KB, EB) to allow for subsequent closer coding and categorizing into broad themes. We used an inductive, thematic approach in which data were examined for patterns using emergent findings from the surveys as sensitizing concepts against which the qualitative data were continuously tested (Charmaz, 2003).

\section{Results}

The significance of people's relationship to the natural environment and its role in experiences of recovery emerged strongly from our qualitative interviews. This data subsequently drove additional quantitative analyses and modifications to the survey for the second wave of data collection. Our qualitative findings are therefore presented first, followed by quantitative results and then a discussion that brings the two sets of findings together.

\section{Qualitative findings}

Almost every person that we interviewed chose to show us the impact of the fires on the natural environment. In a number of cases, this was almost the entire focus of the interview. In instances where interviewees had relocated from a bushfire affected area between the time of the fires and the interviews, this 
focus tended to be less pronounced although in some cases, the damage to the natural environment was described as one of the reasons for relocating. The key themes that emerged in relation to the natural environment included appreciation of the 'bush' in general; the way its devastation during the fires created a deep sense of loss and grief; and the significance of its natural regeneration as a symbol of hope and renewal. These themes were common throughout the interviews and are illuminated further below using selected quotes.

When asked to talk about the most significant aspects of living in their community, several participants proclaimed that the 'bush' or natural environment was the main reason for living there.

[We live here] because we love the bush, the atmosphere, the birds, the flowers, the amenities. [F1]

One of the reasons why we bought the property is we loved the property. We weren't that keen on the house, but we thought we would make do with the house and as you see visually... all the way around I have gullies to look over. [M1]

When talking about the fires that had swept through their communities three to four years before the interviews, the impact on the natural environment was frequently spoken about at length. One couple who had managed to save their house (as had most of their neighbors) still felt the environmental impacts keenly.

But you did have a sense of loss though. there was a sense of loss because you'd lost the feeling of coming home, familiar trees and all that because that was all gone. [F1]

Several interviewees noted that they had experienced an unwelcome change in the way their home was situated within the landscape - from trees surrounding the house to an open outlook, and from a feeling of seclusion to being able to see their neighbors' homes dotted around them. Many of the participants spoke about the 'blackness' that dominated after the fires and recalled the overwhelming effects on them of changes to the environment and how these changes continued to serve as a powerful visual reminder of the disaster and as a symbol of loss. 
It was hard, driving through, it was pretty hard... I could not drive up or down without just, on my own, just crying, just bizarre. Just driving through the place... and this was for months... totally 'nuked'. It was dead, completely dead till they reseeded it... Particularly the early days, you've still got images of cars that are crashed and burned and four horses that are dead and sheep and all sorts which went away quite quickly but it's still what you remember. [M6]

A child who was seven at the time of the interview and four at the time of the fires spoke about the new community he and his family had moved to since the disaster and what he liked about it: 'it's not black, it's more better and nice' [M15]. Similar sentiments regarding the impact of 'blackness' were expressed by many of the adult participants.

After the fires everything was just black and white, the ground had this white powder on it... We thought "how could they ever get that to grow back?" ... All those spots that we really love going to because we walk a lot, they just weren't there... It's taken us a long time to accept that this has changed for us. I think we're probably just starting to become used to walking around and seeing the trees or the different type of vegetation coming back, appreciating it and saying "this is a marvelous bush that can regrow" because we just had that stark reminder of blackened trees. Quite a few of [the trees] didn't come back, many of them didn't come back. [F3]

As seen in the quotes below, this participant and her husband came to recognise their feelings as genuine and legitimate grief, caused by a loss that had profound meaning in their lives.

We ended up going on a trip to England. I was born in England and we thought "we'll get away from all the black and have a break, we'll come back refreshed and be able to cope with it". But when we came back we.... [M5] We went down the 'gurgler'... I would say it took that long for something to kick in, really kick in. We thought that others would need it [grief counselling] because they had lost families, they'd lost houses, all sorts of things. We thought "we're alright" we've got our house, we've got our immediate area". 
Although, as I said, we felt more than sad at the loss of the bush and our favorite places here... What was pointed out was that no matter what, grief is an individual thing and you don't have to compare yourself... grief is grief, so you know, allow your grief to be, if it's there, and that's okay... We were told about the two-year mark that many people had the same thing happen - it's the adrenalin that can take so long to dissipate and then bang! [F3]

Despite a sense of loss, many of the interview participants also felt that seeing the bush regenerate in the months and years after the fires had had a powerful and positive effect on them.

What was great was when you started seeing green come through. I loved it!... I loved that side of it, when you saw it coming back. [F4]

Some spoke about consciously reminding themselves and their families that fire and regeneration were a natural and necessary part of the ecology of the Australian bush.

The bush itself in some ways benefitted from the fire because there are lots of plants that depend on fire for regeneration. [M5]

It did change after the fires, visually and dramatically. It was quite a moonscape after the fires... I think it's normally about a 10-year period until the old trees, the ones that are dead fall over and the ones that were quite severely burned tend to lose that blackness. So, we came out here for the views and everything and then that really did change. I had to just talk to my wife and say "look it will come back, it will come back" [M2]

One interviewee [M6] described how he set up multiple cameras to take time-lapse photography of the recovery of the bush twice per week for several years from 18 different locations on his property. Seeing the wildlife return was similarly attended to and appreciated.

It's recovering quite nicely, and the wildlife is moving back in now, so you can now go in there and you can see koalas again. you can see wallabies and so forth. But it took several 
years for that to happen. And we've had some of the big rare owls around, powerful owl and barking owls, which also indicates we have a good population of possums. [M3]

A participant who described, in a relatively matter-of-fact manner, his dramatic personal escape from the fires, the deaths of neighbors and the loss of his home, became visibly emotional when describing the regeneration of the bush.

Another big deal around here, and for us in particular, is to have been able to observe the way that nature has recovered...you start to see a little green leaf pop out somewhere from a black trunk... you'd find the grass trees starting to sprout and the ferns, the tree ferns, the shoots unrolling... We used some photos of the tree ferns in our Christmas card that year - a symbol of hope and renewal. [M11]

Another interviewee explicitly compared the regrowth in the environment with the potential for, and experience of, personal growth after trauma.

Because with the fire, so much has been sort of obliterated and seeing it all creep back leaf by leaf has been quite humbling in a sense, in the same way that we're growing from it. It's kind of nice to almost feel like you're part of the environment in a sense because nature is growing back from it and we're sort of growing from it... you can really see the devastation but that's okay. I mean look how beautiful it is. It's just an accepted part of the environment... It's kind of nice feeling that it's an accepted part of who I am and it's an accepted part of this amazing environment. [F8]

The quotes above illustrate the powerful connection to the natural environment felt by many of our interview participants. They described grief at its destruction during the fires and also spoke about how it functioned as a powerful symbol of healing and renewal following the disaster. As noted earlier, the prominence of the natural environment in our interview data prompted the research team to focus more closely on this aspect of our survey data as well. Despite its considerable length, our Wave 1 survey had contained only two questions about connection to the environment, and these were included as part of a 
general community attachment scale. Following our interviews, we added additional relevant questions for Wave 2, which allowed us to analyze some of the likely impacts of that connection over the broader sample.

\section{Quantitative findings}

This section presents analyses of the links we found in the quantitative survey between participants' levels of attachment to the environment and their mental health and wellbeing.

\section{Participant characteristics}

Participant descriptive data and prevalence of probable mental health conditions are summarized in Table 1. On average, male participants were older than female participants. Women reported significantly higher rates of fear for life during the 2009 bushfires, whilst no differences were observed in reports of the extent of property loss or losing someone close as a result of the fires. Rates of probable PTSD (general and fire related) and probable major depression within this sample from medium and high impact communities did not differ between genders.

Table 1. Participant descriptive data and rates of mental health conditions by gender

\begin{tabular}{lll}
\hline & Male & Female \\
& $(\mathrm{N}=231)$ & $(\mathrm{N}=366)$ \\
Age & $60 \pm 12$ & $57 \pm 13 *$ \\
Tertiary educated & 75 & 158 \\
& $(32.5 \%)$ & $(43.2 \%)$ \\
Retired & 91 & 125 \\
& $(39.4 \%)$ & $(34.2 \%)$ \\
Property loss $(0-10)$ & $5.42 \pm 3.74$ & $5.93 \pm 3.66$ \\
Lost someone close in fires & 81 & 124 \\
& $(35.1 \%)$ & $(34.4 \%)$ \\
\hline
\end{tabular}


Feared for life

PTSD (general)

PTSD (fire-related)

Major depression

Latent profile analysis

${ }^{*} p<.05$
110

$213 *$

$(49.5 \%)$

$(59.3 \%)$

33

66

(14.3\%)

$(18.1 \%)$

17

41

$(7.4 \%)$

$(11.2 \%)$

25

32

$(10.8 \%)$

$(8.7 \%)$ 
Fit indices for models with 1 to 5 environmental attachment profiles are displayed in Table 2. Based on interpretability of the model and goodness-of-fit indices, the two-profile model was selected as the most favorable solution. This two-profile model groups participants into those with strong and weak attachment to the environment. LMR-LRT identified a maximum solution of three profiles, with an insignificant result returned for the three-profile model. Nylund, Asparouhov, and Muthén (2007) suggest the LMR-LRT is vulnerable to overestimation, therefore the ideal statistical solution contains at most three profiles, but there may be fewer. Entropy was high for both the two-profile and three-profile solutions, .874 and .997 respectively. B-LRT continued to show a significant improvement for each subsequent model (see Table 2), beyond the maximum three profile model identified by the LMR-LRT. The AIC, BIC, and A-BIC continued to decrease with subsequent models. These incremental reductions were modest in comparison to those observed between the one and two profile models. Whilst the four and five profile models showed continued improvement in the B-LRT, AIC, BIC, and A-BIC scores, these models also yielded profiles containing less than $4 \%$ of the sample (and as low as $1 \%$ ), indicating that continuing with more than three profiles was undesirable. While simulation study results indicate that the B-LRT is usually the superior measure (Nylund et al., 2007), in line with these results it has been suggested that this measure may not perform as well in practice (Muthén, 2014). Based on the results there is statistical support for the LPA with three profiles as preferred, however the two-profile model is also statistically well performed, especially considering the high entropy for both the two and three profile models. The preferred LPA model therefore, was ultimately selected based on substantive interpretation. 
Table 2. Five-item model with 2009 environmental attachment as conditional predictor

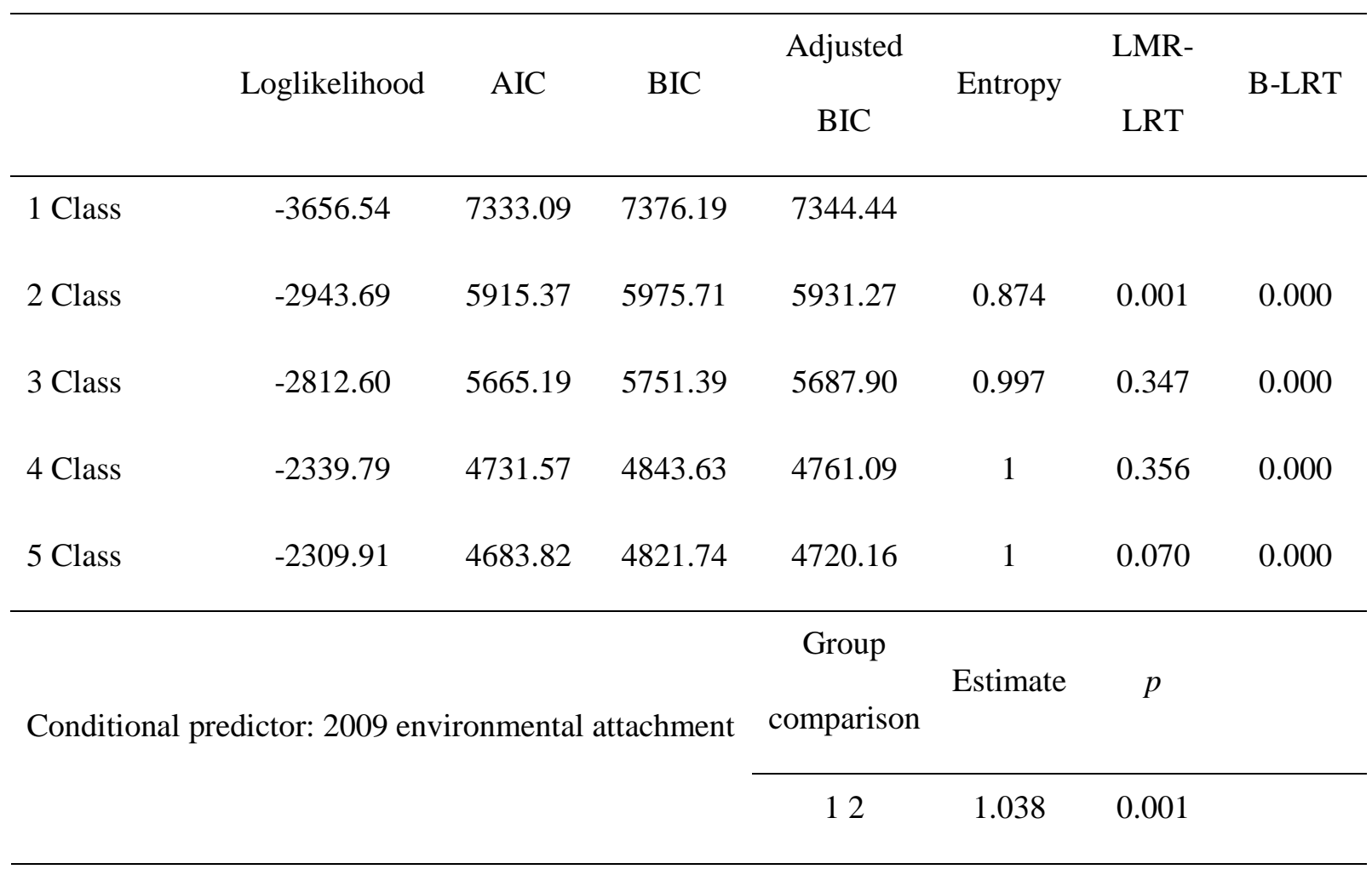

This study was investigating differences in attachment to the environment, and how these attachment differences may relate to mental health, and resilience and growth following a natural disaster. From a utility perspective, to conduct comparisons between environmental attachment and these variables of interest, and to complement the qualitative findings, the simpler two-profile model was preferable, as it sectioned participants into 'strong attachment to environment (SAE)' and 'weak attachment to environment (WAE)' groups (Figure1). Visual inspection of the profiles for the two-profile model demonstrated clear differentiation between profiles across the items measuring environmental attachment and recovery (supported by statistically significant t-tests).

For each profile the plotted mean scores for each of the four items in the LPA are presented in Figure 1. This plot shows that attachment to the natural environment is markedly different between the two profiles at Wave 1 (Mean difference of $-1.51, t(113.92)=-14.74, p<.001$ ) and Wave 2 (Mean difference of $-1.79, t$ $(111.40)=-16.75, p<.001)$. However, these profiles converge/overlap on the item concerning how unhappy participants are with the environmental change as a result of the 2009 bushfires (Mean difference of $.05, t$ $(548)=.36, p=.74)$. The profiles separate again on the items assessing whether the recovery of the 
environment since 2009 had a positive effect on the respondent (Mean difference of $-.71, t(135.11)=-6.17, p$ <.001). Overall the scores for the WAE profile were flatter (mean scores for the 4 items ranged from 2.88 to 3.38) than for the SAE profile (mean scores ranged from 3.34 to 4.56). Reporting retrospective attachment to the natural environment before the fire positively predicted belonging to the SAE profile.

Figure 1. Four item LPA model with retrospective 2009 environmental attachment as a

\section{conditional predictor}

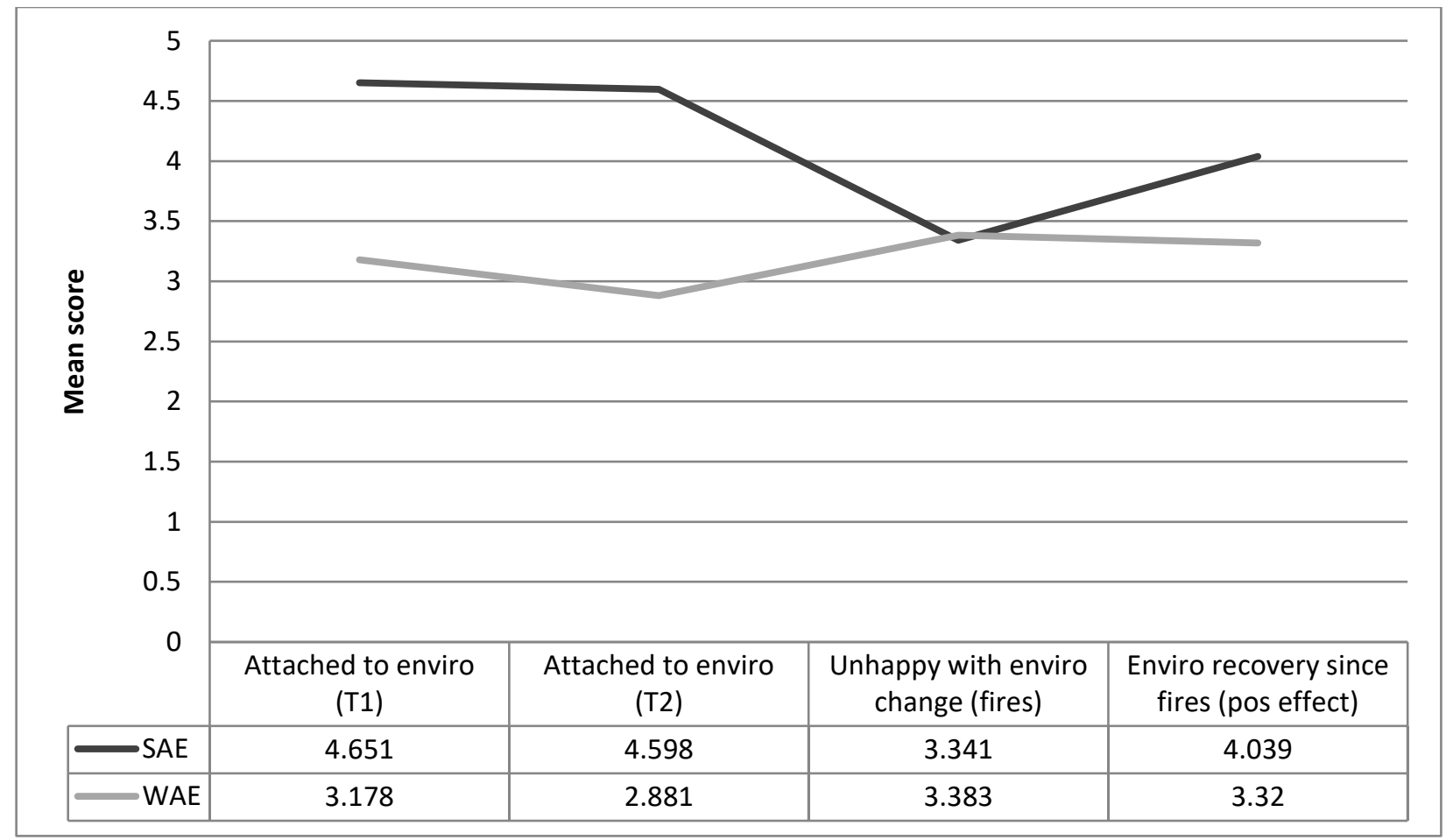

The two profiles differed significantly on a range of factors, displayed in Table 3 . The WAE profile comprised approximately $19 \%$ of the sample $(n=102)$, while the SAE profile was larger, containing $81 \%(n=$ 448). Gender breakdown was comparable across the two profiles and there were no significant differences in fire exposure. The WAE profile was significantly younger and members were more likely to have relocated since 2009. Regarding mental health, participants predicted to belong in the WAE profile reported on average higher psychological distress (K6), higher rates of fire-related symptoms of PTSD, and symptoms of major depression at T2. Participants in the WAE group also had significantly lower levels of resilience, lower posttraumatic growth scores, and reported lower life satisfaction at $\mathrm{T} 2$, and lower anticipated life satisfaction a year on. 


\begin{tabular}{|c|c|c|c|}
\hline & & WAE Profile & SAE Profile \\
\hline & & Mean \pm SD / & Mean \pm SD / \\
\hline & & Count $(\%)$ & Count $(\%)$ \\
\hline & & $N=101$ & $N=449$ \\
\hline \multirow{4}{*}{ Demographic } & Age ${ }^{1}$ & $53 \pm 13$ & $59 \pm 12 *$ \\
\hline & \multirow[b]{2}{*}{ Gender $^{2}$} & $36(36 \%)$ & $180(40 \%)$ \\
\hline & & & \\
\hline & Female & $65(64 \%)$ & $269(60 \%)$ \\
\hline \multirow{5}{*}{ Experiential } & Fear for life 2,3 & $53(54 \%)$ & $246(56 \%)$ \\
\hline & Loss of someone close (yes) ${ }^{2,3}$ & $36(37 \%)$ & $149(34 \%)$ \\
\hline & & & \\
\hline & Extent of property loss ${ }^{1,3}$ & $6.34 \pm 3.80$ & $5.60 \pm 3.64$ \\
\hline & Moved since 2009 (yes) ${ }^{2,3}$ & $50(49 \%)$ & $95(21 \%)^{*}$ \\
\hline \multirow{3}{*}{ Mental health } & $\mathrm{K} 6^{1}$ & $4.49 \pm 4.92$ & $3.32 \pm 4.13 *$ \\
\hline & PTSD fire (yes) ${ }^{2}$ & $15(15 \%)$ & $37(8 \%)^{*}$ \\
\hline & Major depression (yes) ${ }^{2}$ & $15(15 \%)$ & $36(8 \%)^{*}$ \\
\hline \multirow[t]{2}{*}{ Resilience and } & Connor resilience $^{1}$ & $4.18 \pm .81$ & $4.38 \pm .84^{*}$ \\
\hline & $\mathrm{PTG}^{1}$ & $2.92 \pm 1.26$ & $3.29 \pm 1.27 *$ \\
\hline \multirow{3}{*}{ Satisfaction } & Satisfaction with life (now) ${ }^{1}$ & $5.60 \pm 2.23$ & $6.31 \pm 2.04 *$ \\
\hline & & & \\
\hline & Anticipated satisfaction with life (in a year's time) ${ }^{1}$ & $6.41 \pm 2.28$ & $6.98 \pm 2.02 *$ \\
\hline
\end{tabular}




\section{Discussion}

Our qualitative findings indicated that participants felt strongly connected to their local landscape and the natural environment, in many cases describing it as being an important reason for their choosing to live in that location. As noted earlier, commonly used theoretical models developed for understanding disaster recovery have generally emphasised the importance of social and economic capitals (or closely related factors such as political and human capital) for underpinning resilience (see for example Abramson et al., 2014; Aldrich, 2012; Norris et al., 2008). Disaster scholars who have included a focus on place attachment have tended to describe the natural environment as a resource that is important primarily for supporting or disrupting social and/or economic interests (Cox and Perry, 2011; Himes-Cornell et al., 2018; Lawther, 2016; Stedman and Ingalls, 2014). Our findings build on but diverge from this place-attachment disaster-recovery literature, strongly suggesting that the natural environment appeared to have a deep personal significance for individuals over and above any role as a site for social connections or economic activity.

It was less clear from the qualitative results whether this strongly felt connection was experienced as positive or negative for wellbeing in the context of a disaster. Participants clearly felt a strong sense of grief at the loss and devastation of the natural environment and it is certainly plausible that this strength of attachment may have negatively affected their mental health. Such an outcome is suggested by the concept of 'solastalgia' - a word used to describe 'loss of solace' and distress caused by environmental change and physical desolation of people's home environments (Eisenman et al., 2015, Albrecht et al., 2007). Research following severe earthquakes in Christchurch, New Zealand, has also found that love and affection for the landscape, 'topophilia', can turn to a fear of the landscape or 'topophobia' induced by anxiety and insecurity in the wake of a disaster (Bowring, 2013).

Analyses of survey results however, demonstrated that reporting a strong attachment to the natural environment was protective. Respondents who fell into the 'weak attachment to the environment' group experienced increased psychological distress, more symptoms of major depression and fire-related PTSD. They also recorded lower levels of resilience, of post-traumatic growth, and lower current and anticipated life satisfaction. This was independent of individual level of bushfire exposure. They were also significantly more likely to have relocated since the fires $(49 \%$ compared with $21 \%$ of the 'strong attachment to the environment' 
group). While this lower level of environmental attachment may have been a contributing reason for their willingness to move from their community, it is not possible to ascertain from these figures whether lower levels of attachment preceded or followed relocation (Gibbs et al, 2016).

While those reporting strong attachment to the natural environment at the time of the surveys also reported higher levels of attachment before the fires, such retrospective reporting cannot be relied upon to show the direction of the association. It is possible that participants in our study who were experiencing poor mental health reported lack of attachment to the natural environment as a consequence of generalized emotional detachment and that the natural environment itself was relatively inconsequential in this scenario. Moreover, those with poor mental health may also be more inwardly focused and less likely to experience therapeutic benefits from immersion in nature. However, research indicating that people with poor mental health experienced a relatively greater benefit from a nature intervention compared with those with good mental health (Roe and Aspinall, 2011), nonetheless suggests that encouraging exposure to the natural environment for those individuals may still be worthwhile.

Other research can also be drawn on to suggest that a reported strong attachment to the natural environment (especially if we assume this is associated with an increase in immersion in it) is likely to be beneficial. It is known that exposure to chronic stress, experienced by many in a post-disaster setting, is associated with physiological deviations in stress markers such as cortisol which, in turn, have been linked to poor health outcomes including depression and anxiety disorders, immunosuppression and cardiovascular disease (Kondo et al., 2018, Egorov et al., 2017). There are a wide range of posited mechanisms for the therapeutic mental health benefits of exposure to green space. These include buffering chronic stress through impacts on attention, cognition, and coping resources (Ottosson and Grahn, 2008, Roe and Aspinall, 2011, Kaplan, 1995), an associated increase in social contact (Townsend, 2006), and/or associated increase in physical activity (Kondo et al., 2018). An additional theory suggests that a need to feel connected to nature is akin to the psychological importance of belonging to a group, or to something greater than oneself. Hence the effect of nature experience on mental health may also be related to consciously and explicitly held preferences and opinions about nature and one's connection to it. In other words, simply feeling a sense of connection to 
nature, whether or not this is associated with increased exposure, may in itself be associated with wellbeing (Bratman et al., 2012, Mayer et al., 2009, Mayer and Frantz, 2004).

In a study investigating the contribution of the physical environment to a sense of place, Stedman (2003) critiqued the almost exclusive emphasis in much research on the social construction of place attachment, demonstrating that landscape characteristics underpin both place attachment and satisfaction with place. Our findings suggest that Stedman's critique is also relevant in a disaster context. He argues that one's sense of place is thus challenged when physical conditions change dramatically such that preferred meanings become unsustainable requiring active effort to maintain (Stedman, 2003). Such an active effort in the context of dramatic change was evident from our qualitative findings, with many of our interview participants clearly choosing to focus on, and draw solace from, the regeneration of the bush.

\section{Strengths and limitations of this study}

The findings reported in this paper demonstrate the strength of the mixed-methods approach used for the Beyond Bushfires study. Inductive, qualitative methods can facilitate the emergence of unanticipated findings. The participant-guided mobile methods used for interviews in this study allowed participants more power and control compared with a traditional face-to-face interview (Block et al., 2014) and were particularly appropriate for exploring their relationships with their local environment and community. Mixed methods also enabled us to triangulate and confirm our emergent findings regarding the importance of environmental attachment (Johnson et al., 2007) with quantitative data demonstrating the extent and direction of its impact. A limitation of the study, as is commonly the case in disaster recovery research, is that we do not have data demonstrating people's attachment to the environment before the fires. Nor do we have data concerning the amount of time participants spent interacting directly with nature, which could have shed further light on the reasons why reported attachment was correlated with wellbeing.

\section{Conclusion}

Our findings add new insights to an emerging literature focused on the role of the natural environment in supporting wellbeing and resilience following disaster. These findings also demonstrate the value of a mixed-methods approach that incorporated participant-guided interviews - enabling research participants to set their own agenda in a way that disrupted and added considerably to our preconceived ideas about what 
would support recovery. While the qualitative component of the study uncovered the importance of the natural environment to participants, the longitudinal quantitative surveys demonstrated that this environmental attachment was associated with participants' wellbeing despite the grief they expressed as being exposed to its destruction. Further research is certainly required to understand more about the role of the natural environment in disaster recovery. Our results suggest, but cannot prove, that a strong connection to the environment preceded the disaster and consequent mental health impacts. We did not measure how much time our participants actually spent immersed in nature although it is perhaps reasonable to assume that reported connection and time spent are likely to be correlated and related to some of the known therapeutic benefits of nature interventions. The findings also provide some support for the theory that simply feeling a sense of connection could support wellbeing. The protective effect of this sense of connection may be responsible for the somewhat surprising finding that grief over environmental damage did not seem to be associated with a risk of poorer mental health outcomes in our sample.

Additional research in other disaster contexts is also needed. Many of our participants had clearly chosen to live in a disaster-prone environment because of their love of nature. The Australian rural landscape has evolved to regenerate after bushfires and people who live there generally understand this well and to a large extent may view fire as a natural and inevitable part of rural existence. While the consequences of fires on the scale experienced on Black Saturday were nonetheless devastating, far-reaching and long-lasting, such an understanding of fire may also help people to focus on regeneration and renewal within the natural environment as comforting symbols of hope for the future.

Despite many remaining questions, our findings certainly suggest that we should not gloss over the destruction of natural environment and its significance when attempting to understand experiences of, and recovery from, disasters. Landscapes in this context are more than sites for social connection and the impact of their destruction as well as their therapeutic potential should be considered. 
References

ABRAMSON, D., GRATTAN, L.M., MAYER, B., COLTEN, C.E., AROSEMENA, F.A., BEDIMO-RUNG, A., LICHTVELD, M., 2014. The Resilience Activation Framework: a Conceptual Model of How Access to Social Resources Promotes Adaptation and Rapid Recovery in Post-disaster Settings. Journal of Behavioral Health Services \& Research 42, 42-57. https://doi.org/10.1007/s11414-0149410-2

AKAIKE, H. 1987. Factor Analysis and AIC. Psychometrika, 52, 317-32.

ALBRECHT, G., SARTORE, G.-M., CONNOR, L., HIGGINBOTHAM, N., FREEMAN, S., KELLY, B., STAIN, H., TONNA, A. \& POLLARD, G. 2007. Solastalgia: The distress caused by environmental change. Australasian Psychiatry, 15, S95-S98.

ALDRICH, D.P., 2012. Social, not physical, infrastructure: the critical role of civil society after the 1923 Tokyo earthquake. Disasters 36, 398-419. https://doi.org/10.1111/j.1467-7717.2011.01263.x

BEYER, K. M., KALTENBACH, A., SZABO, A., BOGAR, S., NIETO, F. J. \& MALECKI, K. M. 2014. Exposure to neighborhood green space and mental health: Evidence from the survey of the health of Wisconsin. International Journal of Environmental Research and Public Health, 11, 3453-3472.

BLACKMAN, D., NAKANISHI, H., BENSON, A.M., 2017. Disaster resilience as a complex problem: Why linearity is not applicable for long-term recovery. Technological Forecasting and Social Change 121, 89-98. https://doi.org/10.1016/j.techfore.2016.09.018

BLIESE, P. D., WRIGHT, K. M., ADLER, A. B., CABRERA, O., CASTRO, C. A. \& HOGE, C. W. 2008. Validating the primary care posttraumatic stress disorder screen and the posttraumatic stress disorder checklist with soldiers returning from combat. Journal of consulting and clinical psychology, 76, 272281.

BLOCK, K., GIBBS, L., SNOWDON, E. \& MACDOUGALL, C. 2014. Participant guided mobile methods: Investigating personal experiences of communities. SAGE Research Methods Cases, DOI: $10.4135 / 978144627305014536373$.

BOWRING, J. 2013. Topophilia and topophobia in the post-earthquake landscape of Christchurch, New Zealand. Rev. Geo. Sur, 4, 103-122.

BRATMAN, G. N., HAMILTON, J. P. \& DAILY, G. C. 2012. The impacts of nature experience on human cognitive function and mental health. Annals of the New York Academy of Sciences, 1249, 118-136.

BRYANT, R., GALLAGHER, H. C., WATERS, E., GIBBS, L., PATTISON, P., MACDOUGALL, C., HARMS, L., BLOCK, K., BAKER, E., SINNOTT, V., IRETON, G., RICHARDSON, J., FORBES, D. \& LUSHER, D. 2017. Mental health and social networks after disaster. American Journal of Psychiatry, 173, 277-285.

CANN, A., CALHOUN, L. G., TEDESCHI, R. G., TAKU, K., VISHNEVSKY, T., TRIPLETT, K. N. \& DANHAUER, S. C. 2010. A short form of the Posttraumatic Growth Inventory. Anxiety, Stress \& Coping, 23, 127-137.

CELEUX, G. \& SOROMENHO, G. 1996. An entropy criterion for assessing the number of clusters in a mixture model. Journal of Classification, 13, 195.

CHARMAZ, K. 2003. Qualitative interviewing and grounded theory analysis. In: GUBRIUM, J. F. \& HOLSTEIN, A. H. (eds.) Handbook of interview research. Thousand Oaks: Sage

CLARK, S. L. \& MUTHÉN, B. 2009. Relating latent class analysis results to variables not included in the analysis [Online]. Available: https://www.statmodel.com/download/relatinglca.pdf [Accessed 9 Oct. 2018].

CONNOR, K. M. \& DAVIDSON, J. R. T. 2003. Development of a new resilience scale: The ConnorDavidson Resilience Scale (CD-RISC). Depression \& Anxiety (1091-4269), 18, 76.

COX, R. S. \& PERRY, K. M. E. 2011. Like a Fish Out of Water: Reconsidering Disaster Recovery and the Role of Place and Social Capital in Community Disaster Resilience. American Journal of Community Psychology, 48, 395-411. 
CUMMINS, R. A., ECKERSLEY, R., PALLANT, J., VAN VUGT, J. \& MISAJON, R. 2003. Developing a national index of subjective wellbeing: The Australian Unity Wellbeing Index. Social Indicators Research, 64, 159-190.

EGOROV, A. I., GRIFFIN, S. M., CONVERSE, R. R., STYLES, J. N., SAMS, E. A., WILSON, A., JACKSON, L. E. \& WADE, T. J. 2017. Vegetated land cover near residence is associated with reduced allostatic load and improved biomarkers of neuroendocrine, metabolic and immune functions. Environmental Research, 158, 508-521.

EISENMAN, D., MCCAFFREY, S., DONATELLO, I. \& MARSHAL, G. 2015. An ecosystems and vulnerable populations perspective on solastalgia and psychological distress after a wildfire. EcoHealth, 12, 602-610.

EKINS, P., DRESNER, S., DAHLSTRÖM, K., 2008. The four-capital method of sustainable development evaluation. European Environment 18, 63-80. https://doi.org/10.1002/eet.471

GALLAGHER, H. C., BLOCK, K., GIBBS, L., FORBES, D., LUSHER, D., MOLYNEAUX, R., RICHARDSON, J., PATTISON, P., MACDOUGALL, C. \& BRYANT, R. 2019. The effect of group involvement on post-disaster mental health: A longitudinal mulilevel analysis. Social Science \& Medicine, 220, 167-175.

GIBBS, L., GALLAGHER, C., K, B., BAKER, E., BRYANT, R., L, H., IRETON, G., KELLETT, C., SINNOTT, V., RICHARDSON, J., LUSHER, D., FORBES, D., MACDOUGALL, C. \& WATERS, E. 2016. Post-bushfire relocation decision-making and personal wellbeing: A case study from Victoria, Australia. In: AWOTONA, A. (ed.) Planning for Community-based Disaster Resilience Worldwide: Learning from Case Studies in Six Continents. London: Routledge.

GIBBS, L., WATERS, E., BRYANT, R., PATTISON, P., LUSHER, D., HARMS, L., RICHARDSON, J., MACDOUGALL, C., BLOCK, K., SNOWDON, E., GALLAGHER, H. C., SINNOTT, V., IRETON, G. \& FORBES, D. 2013. Beyond Bushfires: Community, Resilience and Recovery - A longitudinal mixed method study of the medium to long term impacts of bushfires on mental health and social connectedness. BMC Public Health, 13, 1036.

HANSEN, M. M., JONES, R. \& TOCCHINI, K. 2017. Shinrin-yoku (forest bathing) and nature therapy: A state-of-the-art review. International Journal of Environmental Research and Public Health, 14, 851899.

HIMES-CORNELL, A., ORMOND, C., HOELTING, K., BAN, N.C., KOEHN, J.Z., ALLISON, E.H., LARSON, E.C., MONSON, D.H., HUNTINGTON, H.P., OKEY, T.A., 2018. Factors Affecting Disaster Preparedness, Response, and Recovery Using the Community Capitals Framework. Coastal Management 46, 335-358. https://doi.org/10.1080/08920753.2018.1498709

JOHNSON, R.B., ONWUEGBUZIE, A.J., TURNER, L.A., 2007. Toward a definition of mixed methods research. Journal of mixed methods research 1, 112-133.

KAPLAN, R. \& KAPLAN, S. 1989. The experience of nature: A psychological perspective, Cambridge, Cambridge University Press.

KAPLAN, S. 1995. The restorative benefits of nature: Toward an integrative framework. Journal of Environmental Psychology, 15, 169-182.

KESSLER, R. C., ANDREWS, G., COLPE, L. J., HIRIPI, E., MROCZEK, D. K., NORMAND, S. L. T., WALTERS, E. E. \& ZASLAVSKY, A. M. 2002. Short screening scales to monitor population prevalences and trends in non-specific psychological distress. Psychological Medicine, 32, 959-976.

KONDO, M. C., JACOBY, S. F. \& SOUTH, E. C. 2018. Does spending time outdoors reduce stress? A review of real-time stress response to outdoor environments. Health \& place, 51, 136-150.

KORPELA, K. M., YLÉN, M., TYRVÄINEN, L. \& SILVENNOINEN, H. 2008. Determinants of restorative experiences in everyday favorite places. Health \& Place, 14, 636-652.

KROENKE, K., SPITZER, R. L. \& WILLIAMS, J. B. 2001. The PHQ-9: Validity of a brief depression severity measure. Journal of general internal medicine, 16, 606-613.

LAWTHER, P.M., 2016. Towards a natural disaster intervention and recovery framework. Disasters 40, 494517. https://doi.org/10.1111/disa.12163 
LO, Y., MENDELL, N. R. \& RUBIN, D. B. 2001. Testing the Number of Components in a Normal Mixture. Biometrika Trust.

MALLER, C., TOWNSEND, M., PRYOR, A., BROWN, P. \& ST LEGER, L. 2006. Healthy nature healthy people: Contact with nature'as an upstream health promotion intervention for populations. Health Promotion International, 21, 45-54.

MAYER, F. S. \& FRANTZ, C. M. 2004. The connectedness to nature scale: A measure of individuals' feeling in community with nature. Journal of Environmental Psychology, 24, 503-515.

MAYER, F. S., FRANTZ, C. M., BRUEHLMAN-SENECAL, E. \& DOLLIVER, K. 2009. Why is nature beneficial? The role of connectedness to nature. Environment and Behavior, 41, 607-643.

MAYUNGA, J.S., 2007. Understanding and applying the concept of community disaster resilience: A capitalbased approach. Summer academy for social vulnerability and resilience building, 1(1), pp.1-16.

MILES, S.B., 2015. Foundations of community disaster resilience: well-being, identity, services, and capitals. Environmental Hazards 14, 103-121. https://doi.org/10.1080/17477891.2014.999018

MCCUTCHEON, A. L. 1987. Latent class analysis. [electronic resource], Newbury Park, [Calif.] ; London : SAGE, c1987.

MCLACHLAN, G. J. \& PEEL, D. 2000. Finite mixture models, New York; Chichester : Wiley, c2000.

MUTHÉN, B. O. 2014 Latent variable mixture modelling: Selecting the number of classes [Online forum comment] [Online]. Available: http://www.statmodel.com/discussion/messages/13/458.html?1477682672 [Accessed 9 Oct 2018].

MUTHÉN, L. K. \& MUTHÉN, B. O. 1998-2015. Mplus User's Guide. Seventh Edition. , Los Angeles, CA, Muthén \& Muthén.

NORRIS, F. H., STEVENS, S. P., PFEFFERBAUM, B., WYCHE, K. F. \& PFEFFERBAUM, R. L. 2008. Community resilience as a metaphor, theory, set of capacities, and strategy for disaster readiness. American Journal of Community Psychology, 41, 127-150.

NYLUND, K. L., ASPAROUHOV, T. \& MUTHÉN, B. O. 2007. Deciding on the Number of Classes in Latent Class Analysis and Growth Mixture Modeling: A Monte Carlo Simulation Study. Structural Equation Modeling 14, 535-569.

OTTOSSON, J. \& GRAHN, P. 2008. The role of natural settings in crisis rehabilitation: How does the level of crisis influence the response to experiences of nature with regard to measures of rehabilitation?

Landscape Research, 33, 51-70.

QSR INTERNATIONAL 2015. NVivo qualitative data analysis software; Version 11. Melbourne.

ROE, J. \& ASPINALL, P. 2011. The restorative benefits of walking in urban and rural settings in adults with good and poor mental health. Health \& Place, 17, 103-113.

SCHWARZ, G. 1978. Estimating the Dimension of a Model. Institute of Mathematical Statistics.

SCLOVE, S. 1987. Application of model-selection criteria to some problems in multivariate analysis. Psychometrika, 52, 333.

SMITH, G.P., WENGER, D., 2007. Sustainable Disaster Recovery: Operationalizing An Existing Agenda, in: Rodríguez, H., Quarantelli, E.L., in Dynes, R.R. (Eds.), Handbook of Disaster Research, Handbooks of Sociology and Social Research. Springer New York, New York, NY, pp. 234-257. https://doi.org/10.1007/978-0-387-32353-4_14

STEDMAN, R. C. 2003. Is it really just a social construction? The contribution of the physical environment to sense of place. Society \&Natural Resources, 16, 671-685.

STEDMAN, R. C. \& INGALLS, M. 2014. Topophilia, biophilia and greening in the red zone. In: TIDBALL, K. G. \& KRASNY, M. E. (eds.) Greening in the red zone: Disaster, resilience, and community greening. Dordrecht: Springer.

STIGSDOTTER, U. K., EKHOLM, O., SCHIPPERIJN, J., TOFTAGER, M., KAMPER-JØRGENSEN, F. \& RANDRUP, T. B. 2010. Health promoting outdoor environments: Associations between green space, 
and health, health-related quality of life and stress based on a Danish national representative survey. Scandinavian Journal of Public Health, 38, 411-417.

TEAGUE, B., MCLEOD, R. \& PASCOE, S. 2010. 2009 Victorian Bushfires Royal Commission: Final Report. Melbourne: Government Printer for the State of Victoria.

TIDBALL, K. G. 2012. Urgent biophilia: Human-nature interactions and biological attractions in disaster resilience. Ecology and Society, 17.

TIDBALL, K. G. \& KRASNY, M. E. 2014. Greening in the red zone: Disaster, resilience and community greening, Dordrecht, Springer

TOWNSEND, M. 2006. Feel blue? Touch green! Participation in forest/woodland management as a treatment for depression. Urban Forestry \& Urban Greening, 5, 111-120.

ULRICH, R. S. 1984. View through a window may influence recovery from surgery. Science, 224, 420-421.

ULRICH, R. S. 1999. Effects of gardens on health outcomes: Theory and research. In: COOPER, C. \& BARNES, M. (eds.) Healing Gardens: Therapeutic Benefits and Design Recommendation. New York: Wiley.

UNISDR, 2015. Sendai Framework for Disaster Risk Reduction 2015-2030. United Nations Office for Disaster Risk Reduction.

VAN DEN BERG, A. E., MAAS, J., VERHEIJ, R. A. \& GROENEWEGEN, P. P. 2010. Green space as a buffer between stressful life events and health. Social Science \& Medicine, 70, 1203-1210.

WILSON, E. O. 1984. Biophilia, Cambridge, Massachusetts, Harvard University Press. 